10 patients have had their pouch excised. The excised pouch did not demonstrate CD. 4 were excised for poor function, 3 for pelvic sepsis, 2 for faecal incontinence and 1 for bleeding. 3 of the 10 subsequently underwent successful revision pouch surgery. 4 other patients are currently diverted with an ileostomy ( 2 because of complications in pregnancy).

We have not identified CD developing in previous UC in our cohort. No children with a diagnosis of indeterminate colitis underwent RPC and IPAA. Children with the diagnosis of indeterminate colitis on initial histology had a subsequent diagnosis of UC on imaging or histology before surgery. The median number of pre-colectomy endoscopies performed was 3 .

Summary and conclusion At median follow up of 10 years, we have not seen a conversion of diagnosis from UC to CD. This contrasts with published experience.

\section{P40 PHENOTYPIC, LABORATORY AND HISTOPATHOLOGICAL ATOPY PROFILES IN A MULTIRACIAL COHORT OF PEDIATRIC EOSINOPHILIC ESOPHAGITIS PATIENTS}

Mark Mahon, Gabriele Devos, Daniela Levanon. Jacobi Medical Center/Albert Einstein

\subsection{6/flgastro-2021-bspghan.49}

Background Eosinophils are a known hallmark of the atopic march that encompasses allergic rhinitis, atopic dermatitis, allergies and asthma, with eosinophilic esophagitis (EoE) recently suggested as the ultimate component of atopic disease. Recent reports point to ethnic and racial disparities between Asian/Caucasian cohorts in eosinophilic disease, however, race-specific atopic patterns are yet to be determined.

Aim To determine racial differences in atopy profiles of pediatric patients diagnosed with EoE.

Methods Started as a quality improvement to be better serve a minority population, a retrospective chart review was performed on pediatric patients with a diagnosis of EoE seen over a decade at a Pediatric Gastroenterology clinic. The clinic serves a diverse minority population, located within a municipal hospital in The Bronx, NY. Inclusion criteria included patients with a diagnosis of EoE defined as symptoms consistent with EoE and confirmation on endoscopic biopsy ( $>15$ eosinophils per high power field). Demographic data (age, race, sex) and atopic variables such as atopy history, serum IgE, absolute eosinophil count (AEC) and esophageal eosinophilia were noted. All variables were stratified according to race and statistical significance was evaluated using medians and proportions.

Results Thirty-four patients were included, and stratified by race. 'Other' included Mixed and Caucasian [table 1]. The subjects at time of EoE diagnosis aged 0.58 to 20 years and male to female ratio of $3: 1$. The median [IQR] age for initial clinical atopy diagnosis (Allergic Rhinitis, Atopic Dermatitis, Asthma or Allergy) was 2 [1,5] years and for EoE diagnosis was $5[3,8]$ for all races combined. No significant difference existed between the racial cohorts for age at first atopy and EoE diagnosis [table 1]. Although, the interval between age at first atopic presentation to the age at EoE diagnosis was clinically shortest for Black/African-Americans, racial difference was not statistically significant, as majority were diagnosed within 12 months of
Abstract P40 Table 1 Variable of Interest in EoE stratified by race

\begin{tabular}{|c|c|c|c|c|c|}
\hline Variable & $\begin{array}{l}\text { Black/African- } \\
\text { American }\end{array}$ & $\begin{array}{l}\text { Hispanic/ } \\
\text { Latino }\end{array}$ & Asian & Other & P-value \\
\hline Subjects n (\%) & $6(18)$ & $11(32)$ & $10(29)$ & $7(20)$ & NA \\
\hline $\begin{array}{l}\text { Age first atopy } \\
\text { [Median (IQR)] }\end{array}$ & $8(2,14)$ & $2(0.33,6)$ & $2.5(1.5,4)$ & $2(0,5)$ & 0.481 \\
\hline $\begin{array}{l}\text { Age EoE dx } \\
\text { [Median (IQR)] }\end{array}$ & $13(5,18)$ & $4(1.5,9)$ & $5(3,7)$ & $3(1.5,8)$ & 0.07 \\
\hline $\begin{array}{l}\text { Absolute Eosinophil } \\
\text { Count [n }(\% \geq 0.35 / \mathrm{nL}\end{array}$ & $3(60)$ & $4(50)$ & 7 (78) & $5(71)$ & 0.785 \\
\hline $\begin{array}{l}\text { Serum lgE } \\
{[n(\% \geq 300)]}\end{array}$ & $4(80)$ & $3(27)$ & $1(10)$ & $2(29)$ & 0.075 \\
\hline $\begin{array}{l}\text { Midesophageal } \\
\text { Eosinophilia [Mean } \\
\text { (IQR)] }\end{array}$ & $48(20,80)$ & $13(3,20)$ & $27(1.5,41)$ & $25(3,41)$ & 0.01 \\
\hline
\end{tabular}

Abstract P40 Table 2 Environmental Allergy Sensitization in multi-racial EoE cohort

\begin{tabular}{llllll}
\hline $\begin{array}{l}\text { Environmental } \\
\text { Allergen } \mathbf{n}(\%)\end{array}$ & $\begin{array}{l}\text { Black/African- } \\
\text { American }\end{array}$ & $\begin{array}{l}\text { Hispanicl } \\
\text { Latino }\end{array}$ & Asian & Other & P-value \\
\hline Tree & $3(100)$ & $2(28.5)$ & $4(44.4)$ & $3(60)$ & 0.255 \\
Grass & $1(50)$ & $2(28.5)$ & $0(0)$ & $3(60)$ & 0.069 \\
Weeds & $3(100)$ & $3(43)$ & $1(11)$ & $3(60)$ & 0.037 \\
Dustmite & $3(100)$ & $4(57)$ & $2(25)$ & $1(20)$ & 0.093 \\
Cat & $2(66)$ & $5(71)$ & $3(37.5)$ & $1(20)$ & 0.344 \\
Dog & $3(100)$ & $6(86)$ & $1(14)$ & $1(20)$ & 0.009 \\
Cockroach & $3(100)$ & $4(57)$ & $4(44)$ & $2(40)$ & 0.465 \\
Mouse & $1(33)$ & $6(86)$ & $2(25)$ & $3(60)$ & 0.132 \\
Mold & $2(100)$ & $2(28.5)$ & $0(0)$ & $0(0)$ & 0.006 \\
\hline
\end{tabular}

symptom onset. Allergen sensitization was tested via either Skin Prick Testing or Serum IgE quantification. There was no racial difference in sensitization (positive test rates) to the 8 common food allergens $(p=0.139)$, which are known triggers of EoE. Environmental allergy testing demonstrated Black/African Americans more likely to be sensitized to weeds, dog and mold than any other racial group [table 2]. No interracial difference was appreciated in terms of Absolute Eosinophil Count and Serum IgE [table 1]. Mid esophageal eosinophilia was more prominent in Black/African-American [table 1], while lower esophageal eosinophilia was most prominent for Hispanic/Latino's subjects, demonstrating a median [IQR] of $40[20,40]$, compared to any other race $(p=0.004)$.

Conclusion Our findings suggest no racial differences in phenotypic presentation of EoE, except for higher allergy sensitization rates to certain environmental allergens in Black/ African-Americans. No racial differences existed regarding laboratory evidence of serum eosinophilia or IgE levels. Histopathological evidence demonstrated racial differences with Black/African-American exhibiting higher mid-esophageal eosinophilia on histopathology. Further study, on a larger scale is required to confirm the complex interplay between race and EoE. 